\title{
INVESTIGATION OF ACCD3 GENE OF MYCOBACTERIUM TUBERCULOSIS IRAQI ISOLATES
}

\author{
Asra'a A Abdul-Jalil' ${ }^{1}$, Zahra M Al-Khafaji ${ }^{2}$, Mushtak T Al-Ouqaili ${ }^{1}$ \\ ${ }^{1}$ Department of Clinical Laboratory Science, College of Pharmacy, University of Anbar, Ramadi, Iraq. ${ }^{2}$ Department of Genetic Engineering, \\ Institute of Genetic Engineering and Biotechnology for Postgraduate Studies, University of Baghdad, Baghdad, Iraq.
}

Email: sc.dr_asraa2017@uoanbar.edu.iq

Received: 13 February 2018, Revised and Accepted: 27 April 2018

ABSTRACT

Objective: Mycobacterium tuberculosis, one of the deadliest human pathogens, causes several million new infections and about 2 million fatalities annually. The cell wall of M. tuberculosis is endowed with a highly impermeable, complex array of diverse lipids such as mycolic acids, which bestow the bacterium with not only virulence but also resistance to host immunity and antibiotics.

Methods: Mycobacterial lipid metabolism has thus emerged as an attractive target for the design and development of novel antimycobacterial therapeutics. The first committed step in the biosynthesis of mycolic acid is the carboxylation of acetyl-CoA to malonyl-CoA which is catalyzed by acetylcoenzyme A carboxylase carboxyl transferase beta subunit ( $\operatorname{ccc} D 3$ ), a primer pairs were designed computationally and used for the amplification of accD3 gene using conventional polymerase chain reaction (PCR) and sequencing the PCR product and analyze the results.

Results: Two sequences of the detection gene (LprM gene) and eight sequences of accD3 gene under study were deposited at NCBI - GenBank database with accession numbers (LC009881, LC009880.1, LC006979, LC008196, LC009412, LC009414, LC034168, LC038020, LC041163, and LC041368) and primer pairs deposited at Probe database/NCBI with accession number Pr032816836.

Conclusion: AccD3 gene is a good drug target in MDR M. tuberculosis strains.

Keywords: Tuberculosis, AccD3gene, Mycolic acid, Primer design, BLAST distance tree.

(C) 2018 The Authors. Published by Innovare Academic Sciences Pvt Ltd. This is an open access article under the CC BY license (http://creativecommons. org/licenses/by/4. 0/) DOI: http://dx.doi.org/10.22159/ajpcr.2018.v11i8.25269

\section{INTRODUCTION}

Tuberculosis (TB) is a debilitating and highly contagious disease that primarily affects the lungs. It was declared by a global health emergency in 1993 by the World Health Organization when approximately 8 million TB cases were estimated, and 1.3-1.6 million deaths occurred from the disease every year, now TB exacerbated by the spread of AIDS [1,2].

AccD3 gene, one of the virulent factors, plays a key role in the biosynthesis pathway of cell wall mycolic acid, and the product of this gene is acetyl-CoA carboxylase carboxyl transferase beta subunit enzyme which is one of the Acc groups. Currently, there are no examples of antibacterial Acc inhibitors in clinical use as antibiotics [3-5]; therefore, $a c c D 3$ represents a very good target for drugs [6].

The aim of this study is to investigate this gene in Iraqi isolates, to be used later for drug design or discovery.

\section{METHODS}

DNA extraction from Mycobacterium tuberculosis isolates and primer design

A total of 50 mycobacterial cultures were collected from the Institute of Chest and Respiratory Disease in Baghdad/Iraq, from May to July 2013. DNA was extracted from prediagnosed mycobacterial cultures and purified by CTAB method $[7,8]$. M. tuberculosis isolates were characterized at molecular level using LprM gene, and two sequences of LprM gene were deposited at GenBank database with accession numbers (LC009880.1 and LC009881), primer pairs were used to amplify this gene to differentiate $M$. tuberculosis from the other types of mycobacteria [9]. The results showed that 43 isolates (86\%) among of 50 isolates were M. tuberculosis.

DNA sequences of accD3 (1488 bp) were retrieved from public database; primers were designed for the gene at two positions,
Segment I from 38 to 831 to give polymerase chain reaction (PCR) product $793 \mathrm{bp}$ and Segment II from 631 to 1482 to give PCR product $851 \mathrm{bp}$. There was an overlapped sequence about $300 \mathrm{bp}$ which was curated manually. The resulted sequence covered the region from 39 to 1482 , these were aligned using Clustal W, and phylogenetic tree was built using NJ method, all these sequences were deposited at NCBI/ nucleotide (GenBank database) with accession numbers (LC006979, LC008196, LC009412, LC009414, LC034168, LC038020, LC041163, and LC041368)

The primer sequences used in PCR experiments are deposited at Probe database/NCBI with accession number (Pr032816836) shown in Table 1.

\section{Amplification of target gene}

AccD3 gene segments (SI and SII) were amplified separately. Each PCR mixture was prepared with $25 \mu$ l of Green Master Mix $\times 2$ (Promega), $17 \mu \mathrm{l}$ of nuclease free water, $2 \mu \mathrm{l}$ of each primer $(\mathrm{F}, \mathrm{R})$ at $10 \mu \mathrm{M}$, and $4 \mu \mathrm{l}$ of DNA (equaling 25-250 ng). Multiple PCR programs were used until reach to the optimum program which gives a good PCR product, the thermocycling conditions for SI and SII were $94^{\circ} \mathrm{C}$ for $5 \mathrm{~min}$, followed by 35 cycles of denaturation at $94^{\circ} \mathrm{C}$ for $1 \mathrm{~min}$, and annealing at $59^{\circ} \mathrm{C}$ for $1.30 \mathrm{~min}$ and $72^{\circ} \mathrm{C}$ for $1 \mathrm{~min}$, then the final extension steps at $72^{\circ} \mathrm{C}$ for $10 \mathrm{~min}$.

PCR amplified products $(10 \mu \mathrm{l})$ and DNA molecular-weight marker (Ladder) were electrophorized on 1\% agarose gel with ethidium bromide staining to verify the size of the amplicon, the resulted PCR products were sequenced (NICEM-USA, Apparatus: Applied Biosystem).

\section{RESULTS AND DISCUSSION}

M. tuberculosis contains multiple versions of $a c c D$ genes that encode $\alpha$ and $\beta$ subunits of at least three distinct multifunctional acyl-CoA carboxylase complexes $[10,11]$. The function of a number of genes 
Table 1: Primer pairs for accD3 gene segments (used in this study)

\begin{tabular}{llll}
\hline Segment I (SI) (38-831) & Forward & GCTAGACCGGGGATCTTTCG & PCR product \\
& Reverse & GCCTTGATCGGTTCCTGACA & 793bp \\
Segment II (SII) (631-1482) & Forward & TGAGTTGCTCTATGGCGACC & PCR product \\
& Reverse & GACAGTCGTAGGGCGAACTC & 851bp \\
\hline
\end{tabular}

PCR: Polymerase chain reaction

Table 2: BLASTing results of accD3 sequences

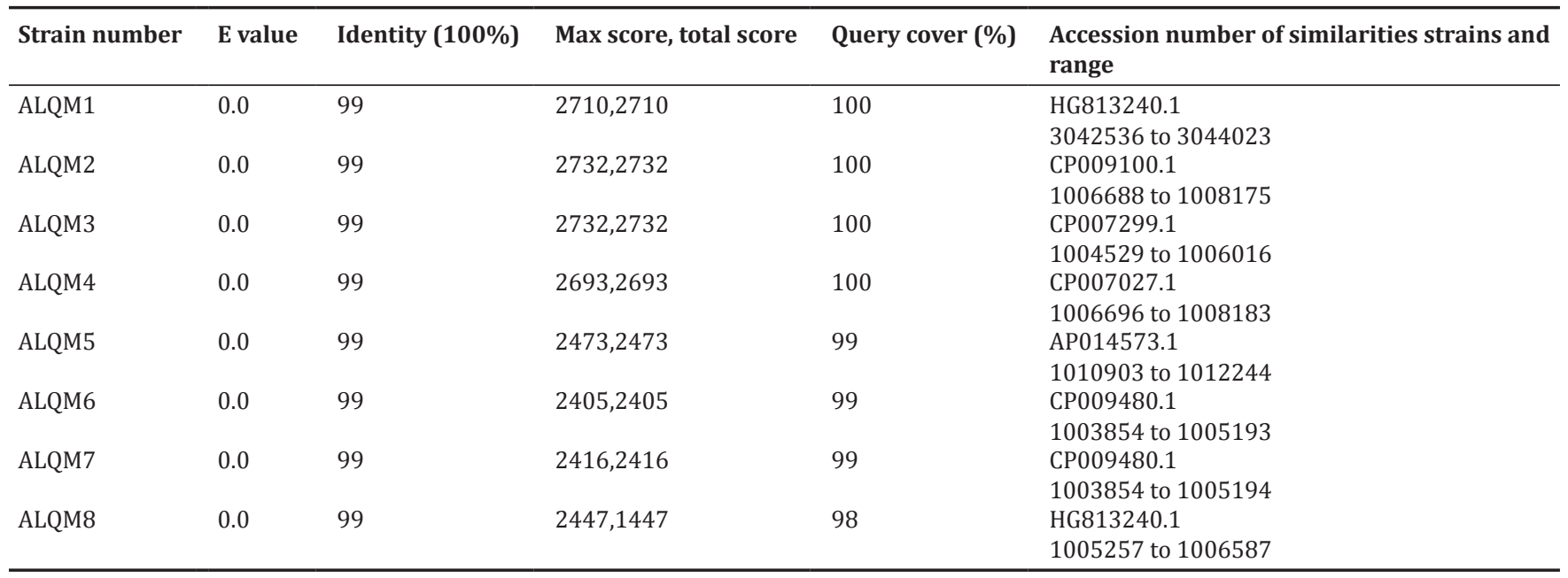

Table 3: The BLAST results of $a c c D 3$ protein sequences with others in Uniprot database

\begin{tabular}{llll}
\hline $\begin{array}{l}\text { Strain } \\
\text { number }\end{array}$ & E-value & Identity & $\begin{array}{l}\text { Accession number of } \\
\text { subject (protein strains) }\end{array}$ \\
\hline ALQM1 & 0.0 & 100 & A0A097ZPG9 \\
ALQM2 & 0.0 & 100 & A0A097ZP91 \\
ALQM3 & 0.0 & 100 & A0A0A1GNR9 \\
ALQM4 & 0.0 & 100 & A0A0A1GN94 \\
ALQM5 & 0.0 & 99.6 & A0A097ZPG9 \\
ALQM6 & 0.0 & 97.8 & A0A0A1GNR9 \\
ALQM7 & 0.0 & 98.4 & A0A0A1GNR9 \\
ALQM8 & 0.0 & 99.6 & A0A056FNG1 \\
\hline
\end{tabular}

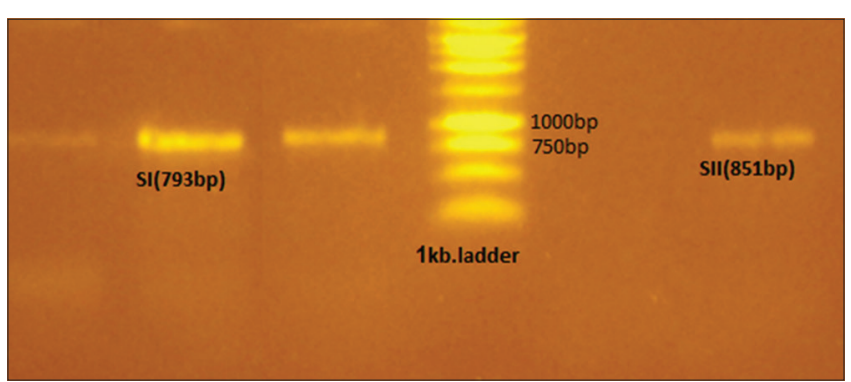

Fig. 1: Gel electrophoresis of $a c c D 3$ (SI and SII) using 1\% agarose staining with ethidium bromide

involved in fatty acid and mycolic acid biosynthesis is known for their role in the survival of pathogenic M. tuberculosis [12-14]. A primer pairs for $\beta$ subunit were designed and used in the amplification of this gene after segmentation of this big gene using conventional PCR technique, the resulted 30 samples were positive out of 43 samples. Amplified accD3 gene (SI and SII) results are shown in Fig. 1.

The PCR product for the two segments of eight isolates was sequenced and in silico analyzed to prove the conformity with accD3 gene sequences of other M. tuberculosis strains in the public databases, Segment I (SI) and Segment II (SII) sequences were BLASTed at expected threshold value 0.05 using BLASTn program and Nucleotide
Collection (nt/nr) database. The results showed these sequences lie in M. tuberculosis strains with identity $98-99 \%$ as shown in Figs. 2 and 3, and the clustering results of these sequences with other Mycobacterium strains are shown in Figs. 4 and 5.

There was an overlap sequence with length about 300 bp between SI and SII, this was removed and merged using Mega 6 and merger tools at EMBOSS package (http://emboss.bioinformatics.nl/cgi-bin/emboss/ merger) [15] to obtain the whole curated sequence. The obtained sequences of accD3 were BLASTed with other strains in GenBank database at E. value 0.00 , and the results were showed that the query sequences were matched the $a c c D 3$ sequences in the databases with query cover $100 \%$ and identity percentage $99 \%$. Table 2 summarizes the results of BLAST program (nucleotide Blast) for the eight obtained accD3 sequences which were designated as (ALQM1, ALQM2, ALQM3, ALQM4, ALQM5, ALQM6, ALQM7, and ALQM8).

AccD3 (Rv0904c) sequences (ALQM1, ALQM2, ALQM3, ALQM4, ALQM5, ALQM6, ALQM7, and ALQM8) as a group (Iraqi strains) were clustered with other strains isolated from different countries (the USA, Russia, India, Japan, India, and Colombia) and registered in NCBI and DDBJ databases. The genetic changes were between the members of phylogenetic tree was 0.02 and the query sequences distributed on different sites. Fig. 6 shows the phylogenetic tree of accD3 nucleotide sequences, using nucleotide sequences.

accD3 sequence translated into protein sequence and the resulted protein sequences were aligned with others in the public database using Uniprot database/Blast (http://www.uniprot.org/blast/). The protein BLAST results are summarized in Table 3.

According to our knowledge, this is the $1^{\text {st }}$ time to design primer pairs for $\operatorname{accD} 3$, and the results showed that the designed primer in this study might be efficient and realistic for the detection of this gene.

\section{ACKNOWLEDGMENT}

We would like to thank the employees at the National Reference Laboratory/National Center of Lung and Respiratory disease in Baghdad for their efforts in the collection of samples from TB patients and special thanks for the manager of this laboratory Dr. Ahmed A. Mankhi. 


\begin{tabular}{|c|c|c|c|c|c|}
\hline Mycobacterium tuberalosis strain ZMC13-264. complete genome & 1363 & 1363 & $98 \%$ & 0.0 & $100 \%$ CP009100.1 \\
\hline Mycobacterium tubercalosis strain OA0290S genome & 1363 & 1363 & $98 \%$ & 0.0 & $100 \%$ cP0089811 \\
\hline Mycobacterium tuberculosis strain $0 \mathrm{~A} 0330 \mathrm{~S}$ genome & 1363 & 1363 & $98 \%$ & 0.0 & $100 \%$ CP008980. 1 \\
\hline Mycobacterium tubercalosis strain 0A0870S genome & 1363 & 1363 & $98 \%$ & 0.0 & $100 \% \underline{\mathrm{CP} 0089781}$ \\
\hline Mycobacterium tubercalosis strain $0 \mathrm{~A} 0920 \mathrm{~S}$ genome & 1363 & 1363 & $98 \%$ & 0.0 & $100 \%$ cP008977. 1 \\
\hline Mycobaderium tuberaulosis strain 0 A0930S genome & 1363 & 1363 & $98 \%$ & 0.0 & $100 \% \underline{\mathrm{CP}} 0009761$ \\
\hline Mycobacterium tubercalosis strain 0A094DS genome & 1363 & 1363 & $98 \%$ & 0.0 & $100 \% \mathrm{cP} 008975.1$ \\
\hline Mycobacterium tuberaulosis strain 0 A $1150 \mathrm{~S}$ genome & 1363 & 1363 & $98 \%$ & 0.0 & $100 \%$ cp008974 \\
\hline Mycobacterium tubercalosis strain OA1170S genome & 1363 & 1363 & $98 \%$ & 0.0 & $100 \% \underline{\mathrm{cP} 008973.1}$ \\
\hline Mycobacterium tuberalosis strain $0 B 070 \times D R$ genome & 1363 & 1363 & $98 \%$ & 0.0 & $100 \% \mathrm{c}$ с 008970.1 \\
\hline Mycobaccerium tuberculosis strain 0 $12123 \mathrm{ND}$ genome & 1363 & 1363 & $98 \%$ & 0.0 & $100 \%$ cp008968. \\
\hline Mycobacterium tubercalosis strain $082220 \mathrm{~S}$ gennome & 1363 & 1363 & $98 \%$ & 0.0 & $100 \%$ с \\
\hline Mycobacterium tuberaulosis strain 082280 S genome & 1363 & 1363 & $98 \%$ & 0.0 & $100 \% \underline{\mathrm{c} P 0089641}$ \\
\hline Mxcobacterium tuberalosis strain $0 \mathrm{~B} 2290 \mathrm{~S}$ genome & 1363 & 1363 & $98 \%$ & 0.0 & $100 \%$ cP008963.1. \\
\hline Mycobaderium tubercalosis strain $0 \mathrm{~B} 2350 \mathrm{~S}$ genome & 1363 & 1363 & $98 \%$ & 0.0 & $100 \%$ cP000962.1 \\
\hline Mycobascterium tuberculosis strain $08259 \times 0 R$ genome & 1363 & 1363 & $98 \%$ & 0.0 & $100 \%$ cP008961.1 \\
\hline Mycobacterium tuberallosis strain $0 B 329 \times 0 R$ genome & 1363 & 1363 & $98 \%$ & 0.0 & $100 \% \mathrm{cP} 008960.1$ \\
\hline Mycobacterium tuberculosis strain $6 A 024 \times D R$ genome & 1363 & 1363 & $98 \%$ & 0.0 & $100 \% \mathrm{cP} 008959.1$ \\
\hline
\end{tabular}

Fig. 2: Alignment results of SI sequence against public database

\begin{tabular}{|c|c|c|c|c|c|}
\hline Mycobacterium tuberculosis strain $\mathrm{AAO05DS}$ genome & 1367 & 1367 & $97 \%$ & 0.0 & $97 \% \underline{\text { CP000893.1 }}$ \\
\hline Mycobacterium tuberculosis strain OA0290S genome & 1367 & 1367 & $97 \%$ & 0.0 & $97 \%$ CP008981.1 \\
\hline Mycobacterium tuberculosis strain OA0330S genome & 1367 & 1367 & $97 \%$ & 0.0 & $97 \% \underline{\underline{C P 008980.1}}$ \\
\hline Mycobacterium tuberculosis strain $0 \mathrm{A0870S}$ genome & 1367 & 1367 & $97 \%$ & 0.0 & $97 \% \underline{\text { CP008978. }}$ \\
\hline Mycobacterium tuberculosis strain $0 \mathrm{A092} D \mathrm{~S}$ genome & 1367 & 1367 & $97 \%$ & 0.0 & $97 \%$ CP008977.1 \\
\hline Mycobacterium tuberculosis strain $0 \mathrm{~A} 0930 \mathrm{~S}$ genome & 1367 & 1367 & $97 \%$ & 0.0 & $97 \%$ CP008976.1 \\
\hline Mycobacterium tuberculosis strain OA094DS genome & 1367 & 1367 & $97 \%$ & 0.0 & $97 \%$ CP008975.1 \\
\hline Mycobacterium tuberculosis strain OA1150S genome & 1367 & 1367 & $97 \%$ & 0.0 & $97 \%$ CP008974.1 \\
\hline Mycobacterium tuberculosis strain OA1170S genome & 1367 & 1367 & $97 \%$ & 0.0 & $97 \%$ CP008973.1 \\
\hline Mycobacterium tuberculosis strain $0 B 026 \times 0 R$ genome & 1367 & 1367 & $97 \%$ & 0.0 & $97 \%$ CP008972.1 \\
\hline Mycobacterium tuberculosis strain $0 B 070 \times 0 R$ genome & 1367 & 1367 & $97 \%$ & 0.0 & $97 \% \underline{\mathrm{CP0008970.1}}$ \\
\hline Mycobacterium tuberculosis strain $0 B 076 \times 0 R$ genome & 1367 & 1367 & $97 \%$ & 0.0 & $97 \%$ CP008969.1 \\
\hline Mycobacterium tuberculosis strain 0B123ND genome & 1367 & 1367 & $97 \%$ & 0.0 & $97 \% \underline{\mathrm{CP} 0089681}$ \\
\hline Mycobacterium tuberculosis strain OB169XDR genome & 1367 & 1367 & $97 \%$ & 0.0 & $97 \% \underline{\underline{C P 008967.1}}$ \\
\hline Mycobaderium tuberculosis strain 0B2180S genome & 1367 & 1367 & $97 \%$ & 0.0 & $97 \%$ CP008966.1 \\
\hline Mycobacterium tuberculosis strain $0 B 2220 S$ genome & 1367 & 1367 & $97 \%$ & 0.0 & $97 \%$ CP008965.1 \\
\hline Mycobacterium tuberculosis strain $0 B 2280 \mathrm{~S}$ genome & 1367 & 1367 & $97 \%$ & 0.0 & $97 \% \underline{\mathrm{CP} 0089641}$ \\
\hline Mycobacterium tuberculosis strain $0 B 2290 \mathrm{~S}$ genome & 1367 & 1367 & $97 \%$ & 0.0 & $97 \% \underline{\mathrm{CP} 0089631}$ \\
\hline
\end{tabular}

Fig. 3: Alignment results of SII against bacterial strains in public database

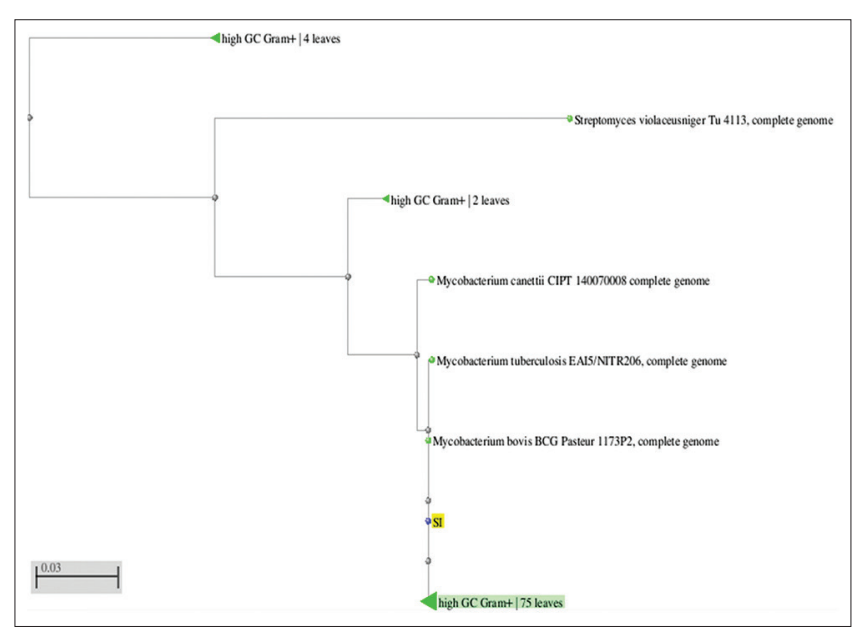

Fig. 4: BLAST distance tree of SI with others in public database

\section{AUTHORS' CONTRIBUTIONS}

Asra'a A. Abdul-Jalil and Zahra M. Alkhafaji achieved bioinformatics analysis and primers design. Mushtak T. Al-Ouqaili helped us in the performing of molecular experiments.

\section{CONFLICTS OF INTEREST}

The authors declare that they have no conflicts of interest.

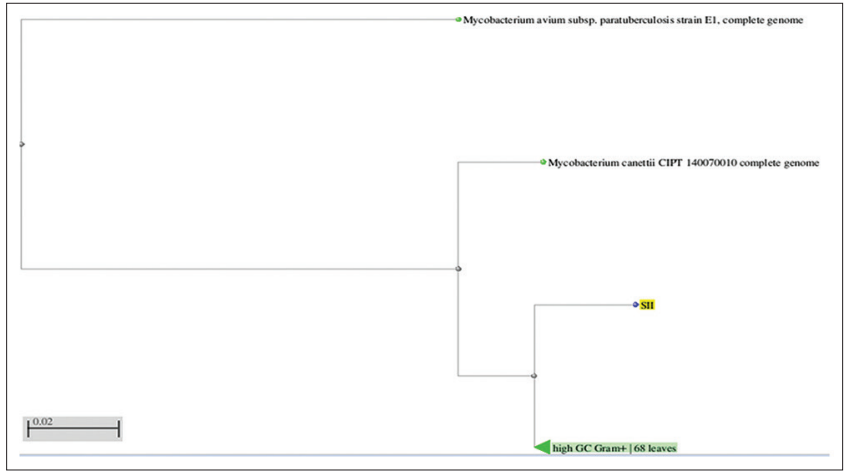

Fig. 5: BLAST distance tree for SII with other Mycobacterium strains

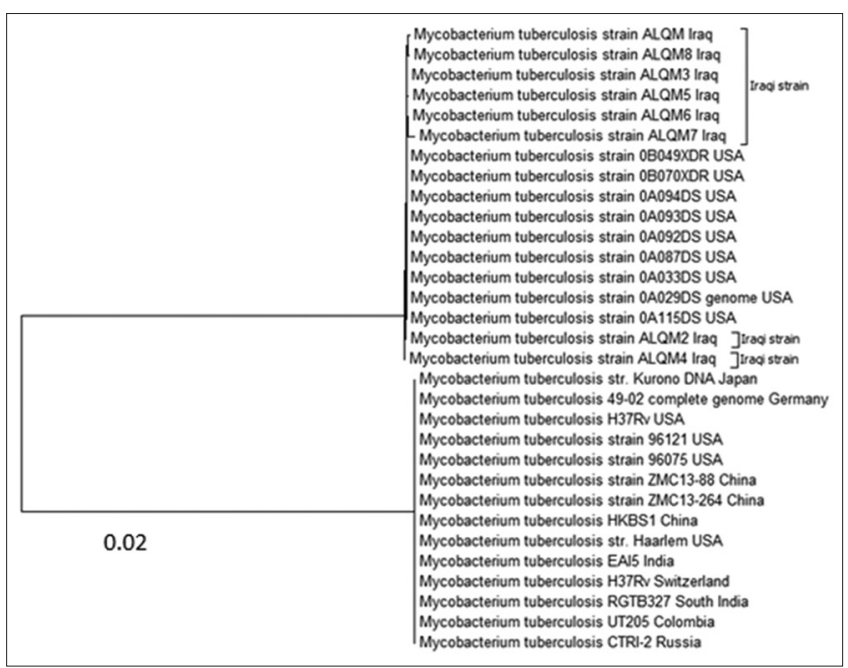

Fig. 6: Phylogenetic relationship of $a c c D 3$ nucleotide sequences

\section{REFERENCES}

1. Earl EA, Altaf M, Murikoli RV, Swift S, O’Toole R. Native new Zealand plants with inhibitory activity towards Mycobacterium tuberculosis. BMC Complementary Altern Med 2010;10:2-7.

2. Ministry of Health of Iraq. New diagnosis of Tuberculosis in Iraq. Baghdad, Iraq: Tech. Rep., Ministry of Health of Iraq; 2012.

3. Polyak SW, Abell AD, Wilce MC, Zhang L, Booker GW. Structure, function and selective inhibition of bacterial acetyl-coa carboxylase. Appl Microbiol Biotechnol 2012;93:983-92.

4. UniProt Consortium. Activities at the universal protein resource (UniProt). Nucleic Acids Res 2014;42:D191-8.

5. Thomas SM, Kothia A, Chandrakar J, Pawar B, Bargaje MA. COST of therapy incurred for tuberculosis patients receiving directly observed therapy (DOT). Int J Pharm Pharm Sci 2015;7:141-4.

6. Takayama K, Wang C, Besra GS. Pathway to synthesis and processing of mycolic acids in Mycobacterium tuberculosis. Clin Microbiol Rev 2005;18:81-101.

7. Huard SB, Lazzarini JL, Ray W. PCR-based method to differentiate the subspecies of the Mycobacterium tuberculosis complex on the basis of genomic deletions. J Clin Microbiol 2013;41:1637-40.

8. Van Helden D, Thomas C, Robin M, Eileen G. Isolation of DNA from Mycobacterium tuberculosis. Methods in Molecular Medicine, Mycobacterium Tuberculosis Protocols Vol. 54. Canada: John Wiley \& Sons; 2001.

9. Abdul-Jalil ZM, Al-Khafaji A, Mankhi Z, Ali AR, Al-Ani M. Study of LprM gene in Iraqi Mycobacterium tuberculosis isolates. World J Pharm Pharm Sci 2014;3:142-51.

10. Holton SJ, King-Scott S, Nasser Eddine A, Kaufmann SH, Wilmanns M. Structural diversity in the six-fold redundant set of acylcoA carboxyltransferases in Mycobacterium tuberculosis. FEBS Lett 2006;580:6898-902

11. Noll $\mathrm{H}$, Bloch H. Studies on the chemistry of the cord factor of 
Mycobacterium tuberculosis. J Biol Chem 1955;224:149-63.

12. Gago G, Kurth D, Diacovich L, Tsai S, Gramajo H. Biochemicaland Structural characterization of an essential acyl coenzyme a carboxylase from Mycobacterium tuberculosis. J Bacteriol 2006;188:477-86.

13. Gibson GR, Brown K, Krumbach A, Dover K, Sahm L, Shioyama H, et al. Acyl-CoA carboxylases (accD2 and $a c c D 3)$ together with a unique polyketide synthase (Cg-pks) are key to mycolic acid biosynthesis in corynebacterianeae like Corynebacteriumglutamicum and Mycobacterium tuberculosis. J Biol Chem 2004;151:1-47.

14. Shaji J, Shaikh M. Drug-resistant tuberculosis: Recent approach in polymer based nanomedicine. Int J Pharm Pharm Sci 2016;8:1-6.

15. Stecher TK, Peterson G, Filipski AD, Kumar S. MEGA6: Molecular evolutionary genetics analysis version 6.0. Mol Biol Evol 2013;30:2725-9. 